\title{
Echocardiography of Right Ventricle in Patients with Schistosomiasis-induced Pulmonary Hypertension
}

\author{
José Maria Del Castillo, Ângela Maria Pontes Bandeira, Eugenio Soares de Albuquerque, Diana Patricia Lamprea, \\ Carlos Antonio da Mota Silveira \\ Pronto-Socorro Cardiológico de Pernambuco (PROCAPE - UPE), Recife, PE - Brazil
}

\begin{abstract}
Introduction: Schistosomiasis is a tropical parasitic disease may cause severe pulmonary hypertension (SIPH), which leads to right ventricular (RV) remodeling and dysfunction, which can be detected by decreased tricuspid annular plane systolic excursion (TAPSE) and variation of RV areas. In normal RV, rich in longitudinal fibers, longitudinal strain prevails, and transverse strain is smaller.
\end{abstract}

Objective: To assess, using conventional echocardiography and two-dimensional RV strain, patients with SIPH, comparing the results with clinical and hemodynamic data and echocardiographic parameters obtained from healthy controls.

Material: Thirty-two patients with SIPH, mean age $45 \pm 12$ years old. Twenty-three healthy controls, mean age $48 \pm 18$ years old.

Methods: RV function parameters (range of areas and TAPSE) and the tricuspid regurgitation gradient were evaluated. Longitudinal and transverse RV strain RV were determined in patients with SIPH and in healthy controls.

Results: Among SIPH patients and healthy controls, the variation of areas was $28 \%$ and $46 \%$, respectively $(p=0.0001)$, TAPSE was $1.9 \mathrm{~cm}$ and $2.2 \mathrm{~cm}(p=0.02)$; tricuspid regurgitation gradient was $76 \mathrm{mmHg}$ and $28 \mathrm{mmHg}(p=0.0001)$; RV sidewall longitudinal strain $-22 \%$ and $-37 \%(p=0.0001)$; and transverse strain of $39 \%$ and $21 \%(p=0.001)$.

Conclusion: Patients with SIPH changed the RV strain pattern with increased transverse strain, probably due to RV adaptation to pressure overload. Conventional echocardiography was also useful to assess RV function in SIPH. (Arq Bras Cardiol: Imagem cardiovasc. 2016;29(3):84-91)

Keywords: Hypertension, Pulmonary; Schistosomiasis Mansoni; Ventricular Remodeling; Strain; Echocardiography.

Table of acronyms

\begin{tabular}{l}
\hline TTE: transthoracic echocardiography \\
SIPH: schistosomiasis-induced pulmonary hypertension \\
NYHA: New York Heart Association functional classification \\
PCWP: pulmonary capillary wedge pressure \\
PVR: pulmonary vascular resistance \\
SLG: global longitudinal strain \\
ST: speckle tracking \\
STG: global transverse strain \\
TAPSE: tricuspid annular plane systolic excursion \\
RV: right ventricle \\
LV: left ventricle
\end{tabular}

Mailing Address: José Maria Del Castillo •

Rua Jorge de Lima 245, apto. 303. Postal Code 51160-070, Salute,

Imbiribeira, Recife, PE - Brazil

E-mail: castillojmd@gmail.com

Manuscript received February 26, 2016; revised March 10, 2016; accepted May 10, 2016.

DOI: $10.5935 / 2318-8219.20160023$

\section{Introduction}

Schistosomiasis, popularly known as "snail fever", is an endemic parasitic disease of tropical regions. Produced by flatworms of the genus Schistosoma, its intermediate host are snails of the genus Biomphalaria and the human being is its definitive host. There are six species of Schistosoma. The species $S$. mansoni is found in the American continent. Human beings plagued with these species eliminate eggs in feces and contaminate the water where there are snails. Infected snails continue the reproductive cycle and eliminate cercariae, provided with forked tails, which penetrate the human skin and are transformed into schistosolum, some tailless species that migrate through the blood vessels. Most of these are destroyed by eosinophils, but those reaching the lungs, through the systemic veins and the pulmonary artery, combine with tissue proteins and carbs becoming virtually undetectable, blocking small arteries and causing perivascular inflammatory reaction. Young larvae migrate through the pulmonary veins to the systemic circulation until they settle in the liver and in intestinal venous plexus, where they produce eggs that are dragged into the bloodstream. Those who cross the intestinal wall are eliminated through feces and complete the cycle. There are the hepatosplenic, hepatointestinal, liver and vascular pulmonary forms. The hepatosplenic and hepatointestinal forms are the most common ones. 
Pulmonary arterial hypertension is a serious complication of hepatosplenic schistosomiasis, ${ }^{1}$ but it can occur in all forms of schistosomiasis, ${ }^{2}$ with an estimated prevalence of $9.6 \%{ }^{3}$ to $25 \% .^{4}$ Schistosomiasis-induced pulmonary arterial hypertension (SIPH) occurs when the eggs of schistosomes escaping the immune reaction of the skin reach the lung parenchyma. ${ }^{5}$ Increased pulmonary blood flow caused by arteriovenous fistulas that occur in portal hypertension favors this migration and produces arteriolar obstruction and perivascular inflammation ${ }^{6}$ with formation of local granuloma and secondary fibrosis. ${ }^{7,8}$ Patients may develop precapillary or post-capillary SIPH when the pulmonary venous system is impaired. ${ }^{9,10}$

Right ventricular (RV) dysfunction is related to chronic increase of pulmonary pressure. Although it is difficult to evaluate the geometry of this chamber, some echocardiographic parameters detect systolic dysfunction, such as tricuspid annular plane systolic excursion (TAPSE) and the ratio of RV systolic and diastolic areas. These data, however, are global, not always expressing the actual right ventricular dysfunction.

Conventional Doppler echocardiography is a useful tool to evaluate SIPH, showing RV dilatation and hypertrophy and pulmonary trunk dilatation, allowing to estimate the flow velocities of the right and left chambers and the presence and degree of pulmonary hypertension.

The introduction of imaging techniques such as cardiac strain, initially applied to the left ventricle (LV), can be used to study the RV. There are few studies correlating the RV function with cardiac strain. ${ }^{11}$

The helical heart shape described by anatomists, supported by Torrent-Guasp ${ }^{12}$ and validated by diffusion tensor imaging, ${ }^{13}$ is formed by a basal band, which involves the ventricles with predominantly circular fibers and an apical band that surrounds the LV, consisting of a subendocardial descending segment and a subepicardial ascending segment, both crossed at a virtually straight angle. Sequential depolarization of these segments causes, in the LV, a twisting movement during systole and a counter-twisting movement during diastole, responsible for ventricular ejection and rapid ventricular filling. ${ }^{14}$ The RV is formed by fibers from the basal band and oblique fibers from the ascending segment of the apical band. These fibers have a nearly parallel arrangement, with no twisting movement. The RV has a predominantly longitudinal strain. The fewer circular fibers responsible for increasing the systolic wall thickening produce a less expressive transverse strain.

Myocardial strain can be detected by speckle tracking (ST), which tracks acoustic marks of two-dimensional echocardiography following the trajectory of small myocardial segments, measuring its strain in orthogonal planes. AS the RV free wall is less influenced by the LV movement, it is more appropriate to assess the right ventricular strain.

\section{Objective}

This observational and prospective study aims to evaluate the RV systolic function and contractile mechanics, analyzing longitudinal and transverse strain in patients with schistosomiasis, with pre-capillary pulmonary hypertension.
Additionally, it seeks to establish myocardial strain patterns associated with RV pressure overload. The results are compared with clinical and hemodynamic data and with echocardiography tests on healthy controls.

\section{Material and methods}

Thirty-two patients with schistosomiasis with precapillary pulmonary hypertension (mean pulmonary artery pressure higher than $30 \mathrm{mmHg}$ and pulmonary capillary pressure lower than $15 \mathrm{mmHg}$ ) with mean age of $45 \pm 12$ years (variation of 21 to 66 years) have been studied. Twenty of these are females. For comparison purposes, 23 healthy controls with mean age $48 \pm 18$ years (variation of 16 to 70 years), 14 females, were studied. All patients and healthy controls signed the declaration of conformity issued by the Research Ethics Committee of PROCAPE-UPE.

All patients underwent clinical examination, hemodynamic study and conventional transthoracic echocardiography (TTE) with two-dimensional strain analysis using the ST technique. Healthy controls underwent echocardiography only. ${ }^{15}$

Clinical examination determined the functional class according to the recommendations of the NYHA.

The hemodynamic study determined the mean pulmonary artery and right atrial pressure, pulmonary capillary wedge pressure (PCWP), cardiac index, pulmonary vascular resistance (PVR) and $\mathrm{O}_{2}$ saturation in the pulmonary artery.

Conventional echocardiography was used to calculate the LV dimensions, diastolic wall thickness, LV systolic shortening fraction, RV linear dimensions, RV diastolic anterior wall thickness, systolic variation of the RV areas, pulmonary artery diameter and tricuspid annular plane systolic excursion (TAPSE).

Spectral Doppler was used to determine tricuspid regurgitation velocities and the full RV outflow tract flow velocity.

Two-dimensional strain (ST) was used to measure the RV global longitudinal strain (GLS) and the longitudinal strain in the lateral and septal walls, the RV global transverse strain (GTS) and the transverse strain in the lateral and septal walls. The LV GLS was also calculated. Figure 1 shows the RV longitudinal and transverse strain in a healthy control, and Figure 2 shows the RV longitudinal and transverse strain in a patient with SIPH.

Echocardiography was performed using the device IE33 (Philips Medical Systems, Andover, MA) and the scanned images were evaluated using the software Qlab Philips V9.1.

Means and standard deviations of the data were calculated. For the statistical analysis of the differences between healthy controls and patients with SIPH, the " $\mathrm{t}$ " test was used. ANOVA with Bonferroni test was used to evaluate the variables with the respect to the functional class. Differences were considered significant when $\mathrm{p}<0.05$.

\section{Results}

Age and weight showed no statistically significant difference between healthy controls and patients with SIPH, but the height and body surface area were significantly smaller in patients with SIPH (Table 1). 


\section{Original Article}

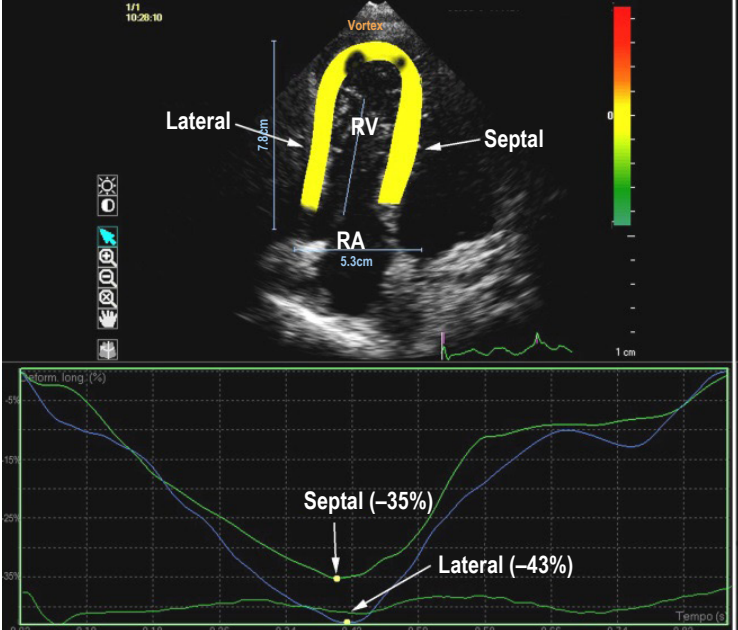

A

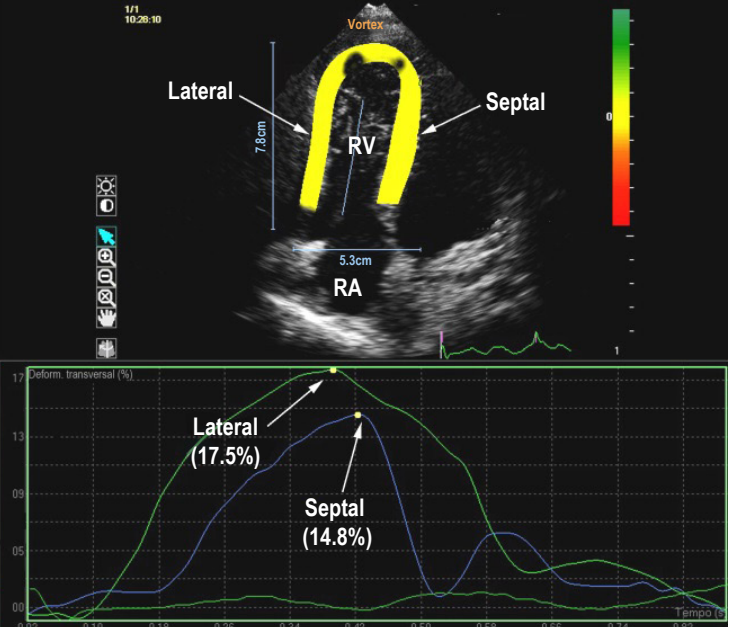

B

Figure 1 - Two-dimensional echocardiography obtained from the apical position in a healthy control. A- evaluation of longitudinal strain in the RV lateral and septal walls. $B$ - evaluation of transverse strain in the same walls. RV: right ventricle; $R A$ : right atrium.

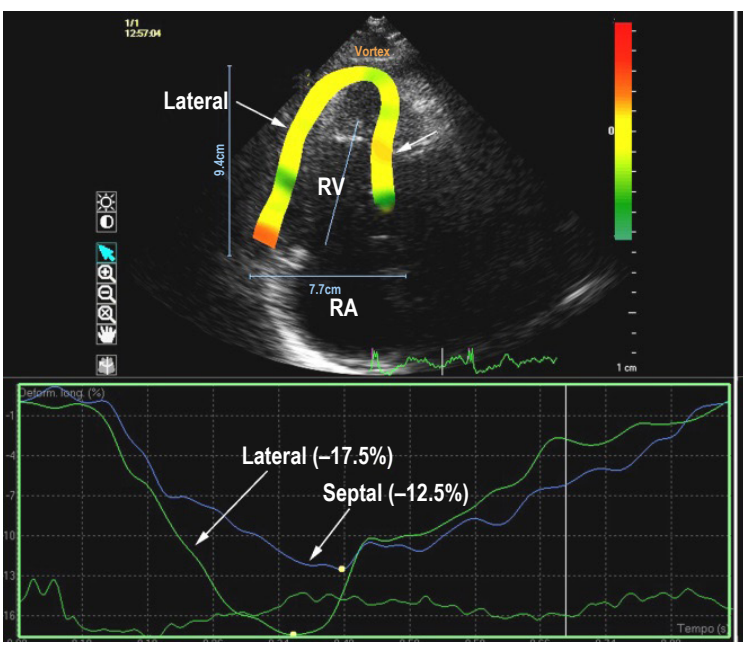

A

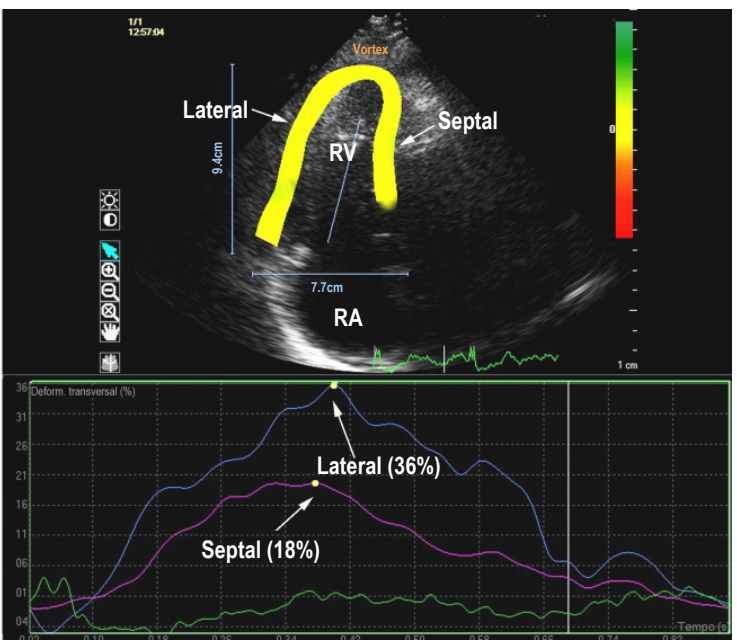

B

Figure 2 - Two-dimensional echocardiography obtained from the apical position in patients with SIPH. A - longitudinal strain of the RV lateral and septal walls. $B$ - transverse strain obtained in the same walls. RV: right ventricle; $R A$ : right atrium.

Table 1 - Demographic data

\begin{tabular}{lccccc}
\hline Group & & $\begin{array}{c}\text { Age } \\
\text { (years) }\end{array}$ & $\begin{array}{c}\text { Weight } \\
(\mathbf{k g})\end{array}$ & $\begin{array}{c}\text { Height } \\
(\mathbf{c m})\end{array}$ & $\begin{array}{c}\text { BS } \\
\left(\mathbf{m}^{2}\right)\end{array}$ \\
\hline \multirow{2}{*}{ Control } & M & 48.04 & 68.96 & 165.83 & 1.75 \\
& SD & 17.60 & 12.12 & 8.73 & 0.18 \\
SIPH & M & 44.59 & 65.25 & 161.47 & 1.67 \\
P & SD & 12.20 & 11.40 & 8.00 & 0.19 \\
\hline
\end{tabular}

M: median; SD: standard deviation; BS: body surface; *: statistically significant. 
There were six patients with SIPH in functional class I (18.8\%), fifteen in functional class II (46.9\%), eight in functional class III (25.0\%) and three in functional class IV $(9.3 \%)$. Comparing the echocardiographic parameters with the increase in functional class, there was a progressive decrease in the LV GLS, RV longitudinal strain (global, lateral and septal), TAPSE, and the percentage of RV areas of variation (Chart 1).

Cardiac catheterization data showed mean pulmonary artery pressure increase, mean right atrial pressure increase and pulmonary vascular resistance increase. Cardiac index was decreased and $\mathrm{O}_{2}$ saturation in the pulmonary artery at a limit close to the minimum, normal. PCWP presented a mean value in the upper limit of normality (Table 2).

LV systolic and diastolic diameters were smaller in patients with SIPH and diastolic interventricular septal thickness was greater. Left ventricular mass and mass index showed no significant differences, but the relative wall thickness was greater in patients with SIPH. LV shortening fraction was smaller in patients with SIPH (Table 3).

RV inflow tract dimensions and free wall thickness were greater in patients with SIPH. The TAPSE and the percentage of variation of RV areas were decreased in patients with $\mathrm{SIPH}$ (Table 4). The pulmonary artery diameter was greater in patients with SIPH $(40.4 \pm 10.0 \mathrm{~mm})$ than in healthy controls $(23.4 \pm 6.0 \mathrm{~mm}, \mathrm{p}<0.0001)$.

The LV GLS was smaller in patients with SIPH. GLS of the septal wall and RV lateral wall was significantly decreased in patients with SIPH. The RV sidewall GTS was increased in patients with $\mathrm{SIPH}$, but the septal transverse strain showed no significant difference (Table 5).

Significant correlations were observed between the percentage of RV areas of variation with the RV GLS (Chart 2) and between the percentage of RV areas of variation with the longitudinal strain of the right atrial lateral wall.

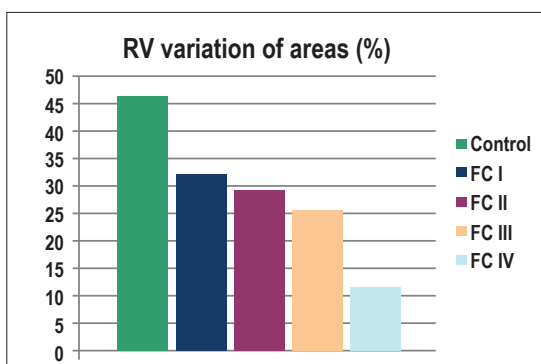

A

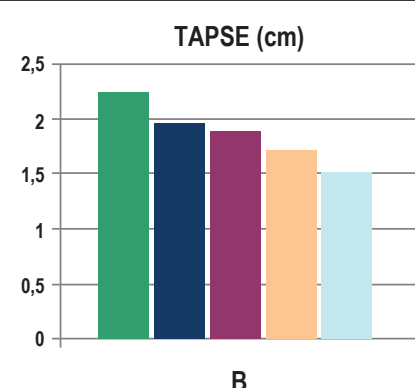

B
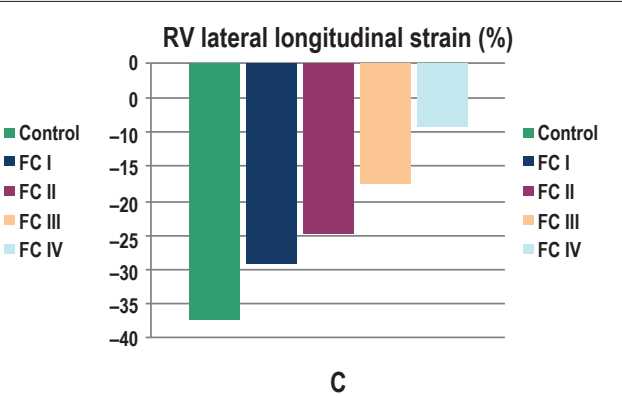

Chart 1 - Analysis of variance of RV echocardiographic parameters with respect to the functional class. A - variation of RV areas; $B-$ tricuspid annular plane systolic excursion (TAPSE); C - RV side wall longitudinal strain. Control: healthy controls; FC I, FC II, FC III and FC IV: NYHA functional class in patients with SIPH.

Table 2 - Cardiac catheterization data

\begin{tabular}{|c|c|c|c|c|c|c|c|}
\hline Group & & $\begin{array}{c}\text { MRAP } \\
(\mathrm{mmHg})\end{array}$ & $\begin{array}{c}\text { MPAP } \\
(\mathrm{mmHg})\end{array}$ & $\begin{array}{c}\mathrm{Cl} \\
\left(\mathrm{l} / \mathrm{m} / \mathrm{m}^{2}\right)\end{array}$ & $\begin{array}{l}\text { PVR } \\
\text { (UW) }\end{array}$ & Sat $\mathrm{O}_{2} \mathrm{PA}(\%)$ & $\begin{array}{c}\text { PCWP } \\
(\mathrm{mmHg})\end{array}$ \\
\hline \multirow{2}{*}{ SIPH } & $M$ & 11.41 & 63.47 & 2.57 & 16.78 & 65.71 & 12.00 \\
\hline & $\mathrm{SD}$ & 5.24 & 11.77 & 0.69 & 7.38 & 6.88 & 2.96 \\
\hline Normal Values ${ }^{15}$ & & $0-8$ & $9-16$ & $2.8-4.2$ & $3.1-4.2$ & $65-75$ & $2-12$ \\
\hline
\end{tabular}

Table 3 - LV dimensions and function

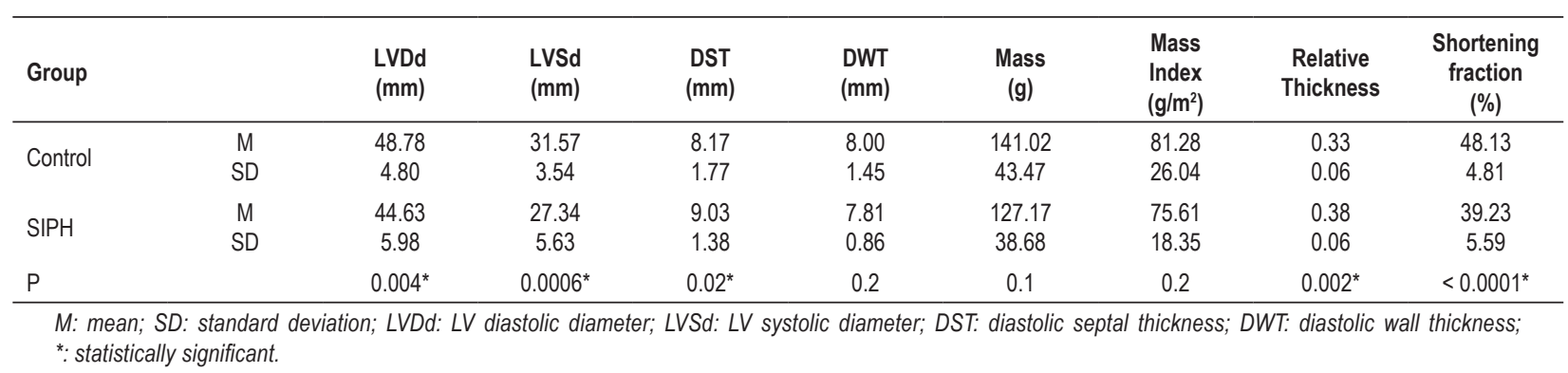


Del Castillo et al.

Right ventricle in PH due to schistosomiasis

\section{Original Article}

Table 4 - RV dimensions and function

\begin{tabular}{|c|c|c|c|c|c|c|c|c|}
\hline Group & & $\begin{array}{l}\mathrm{RV}_{1} \\
(\mathrm{~mm})\end{array}$ & $\begin{array}{l}\mathrm{RV}_{2} \\
(\mathrm{~mm})\end{array}$ & $\begin{array}{l}\mathrm{RV}_{3} \\
(\mathrm{~mm})\end{array}$ & $\begin{array}{c}\text { RVDWT } \\
(\mathrm{mm})\end{array}$ & $\begin{array}{c}\text { TAPSE } \\
(\mathrm{cm})\end{array}$ & $\begin{array}{c}\text { Variation of } \\
\text { areas } \\
\text { (\%) }\end{array}$ & $\begin{array}{l}\text { Tricuspid } \\
\text { gradient } \\
(\mathrm{mmHg})\end{array}$ \\
\hline Control & $\begin{array}{c}M \\
S D\end{array}$ & $\begin{array}{c}32.50 \\
4.30\end{array}$ & $\begin{array}{c}26.16 \\
3.99\end{array}$ & $\begin{array}{c}68.67 \\
7.38\end{array}$ & $\begin{array}{l}5.03 \\
0.62\end{array}$ & $\begin{array}{l}2.24 \\
0.37\end{array}$ & $\begin{array}{c}46.30 \\
4.73\end{array}$ & $\begin{array}{c}28.00 \\
3.13\end{array}$ \\
\hline SIPH & $\begin{array}{c}M \\
S D\end{array}$ & $\begin{array}{c}44.65 \\
5.87\end{array}$ & $\begin{array}{c}39.49 \\
8.19\end{array}$ & $\begin{array}{c}79.01 \\
9.16\end{array}$ & $\begin{array}{l}8.99 \\
2.13\end{array}$ & $\begin{array}{l}1.88 \\
0.40\end{array}$ & $\begin{array}{l}28.20 \\
10.79\end{array}$ & $\begin{array}{l}75.63 \\
22.65\end{array}$ \\
\hline P & & $0.0001^{*}$ & $0.0001^{*}$ & $0.0001^{*}$ & $0.0001^{*}$ & $0.02^{*}$ & $0.0001^{*}$ & $0.0001^{*}$ \\
\hline
\end{tabular}

M: mean; $S D$ : standard deviation; $R V_{1}: R V$ basal transverse diameter; $R V_{2}: R V$ mean transverse diameter; $R V_{3}: R V$ longitudinal diameter; $R V D W T: R V$ diastolic free wall thickness; TAPSE: tricuspid annular plane systolic excursion; Variation of areas: systolic variation of $R V$ areas; *: statistically significant.

Table 5 - LV and RV myocardial strain

\begin{tabular}{|c|c|c|c|c|c|c|c|c|}
\hline Group & & $\begin{array}{c}L_{\text {glolo }} \text { LS } \\
(\%)\end{array}$ & $\begin{array}{c}\mathrm{RV}_{\text {glob }} \mathrm{LS} \\
(\%)\end{array}$ & $\begin{array}{c}\mathrm{RV}_{\text {sep }} \mathrm{LS} \\
(\%)\end{array}$ & $\begin{array}{c}\mathrm{RV}_{\text {lat }} \mathrm{LS} \\
(\%)\end{array}$ & $\underset{(\%)}{\mathrm{RV}_{\text {glob }}} \mathrm{TS}$ & $\underset{(\%)}{\mathrm{RV}_{\text {sep }} \mathrm{TS}}$ & $\begin{array}{c}\mathrm{RV}_{\text {lat }} \mathrm{TS} \\
(\%)\end{array}$ \\
\hline Control & $\begin{array}{l}M \\
S D\end{array}$ & $\begin{array}{c}-18.22 \\
1.04\end{array}$ & $\begin{array}{c}-18.40 \\
3.30\end{array}$ & $\begin{array}{c}-20.03 \\
7.32\end{array}$ & $\begin{array}{c}-37.05 \\
12.40\end{array}$ & $\begin{array}{c}14.63 \\
3.24\end{array}$ & $\begin{array}{c}16.20 \\
4.10\end{array}$ & $\begin{array}{c}20.75 \\
5.88\end{array}$ \\
\hline SIPH & $\begin{array}{l}M \\
\text { SD }\end{array}$ & $\begin{array}{c}-14.55 \\
3.61\end{array}$ & $\begin{array}{c}-14.96 \\
4.82\end{array}$ & $\begin{array}{c}-14.82 \\
5.58\end{array}$ & $\begin{array}{c}-22.15 \\
10.25\end{array}$ & $\begin{array}{l}19.82 \\
12.28\end{array}$ & $\begin{array}{l}18.37 \\
10.59\end{array}$ & $\begin{array}{l}38.79 \\
29.87\end{array}$ \\
\hline$p$ & & $0.0001^{*}$ & $0.002^{*}$ & $0.004^{*}$ & $0.0001^{*}$ & $0.01^{*}$ & 0.09 & $0.0010^{*}$ \\
\hline
\end{tabular}

M: mean, $S D$ : standard deviation; $L V_{\text {glob }} L S: L V$ global longitudinal strain; $R V_{\text {glob }} L S: R V$ global longitudinal strain; $R V_{\text {sep }} L S: R V$ septal longitudinal strain; $R V_{\text {lat }} L S: R V$ lateral wall longitudinal strain; $R V_{\text {glob }} T S: R V$ global transverse strain; $R V_{\text {sep }} T S: R V$ septal transverse strain; $R V_{\text {lat }} T S$ : $R V$ lateral wall transverse strain; *: statistically significant.

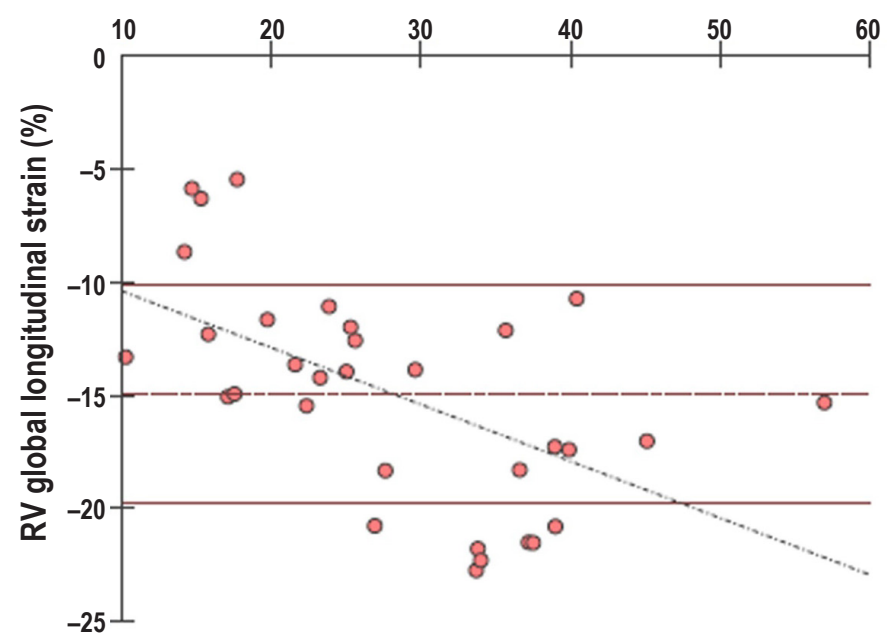

$\mathrm{RV}$ variation of areas $(\%) p=0.0008$

Chart 2 - Pearson's linear regression between the right ventricle global longitudinal strain and right ventricular variation of areas. 


\section{Discussion}

The lower height and body surface of patients with SIPH may be related to chronic and limiting evolution of schistosomiasis and their underprivileged social condition.

The mixed venous oxygen saturation of the pulmonary artery by cardiac catheterization at the lower limit of normality suggests lower $\mathrm{O}_{2}$ supply due to decreased peripheral saturation, especially in the most severe patients. The threshold PCWP was equal to or smaller than $15 \mathrm{mmHg}$, a maximum normality value recommended by the European Society of Cardiology. ${ }^{16}$ This value was used to select patients with precapillary SIPH.

The smaller LV dimension in patients with SIPH may be related to $\mathrm{RV}$ dilatation and decreased flow to the left chambers. Increased septal wall thickness and relative LV wall thickness is secondary to RV hypertrophy. Decreased LV shortening fraction is a consequence of anomalous septal motion produced by right ventricular hypertrophy and left ventricular dysfunction due to low cardiac output in the more severe cases (see decreased cardiac index in Table 2).

The geometry of the right ventricular chamber makes it difficult to evaluate its morphology and volume with conventional echocardiography. The percentage variation of the RV inflow tract area shows reasonable correlation with the patients' decreased functional capacity according to the NYHA criteria (Chart 1A). RV anterior wall thickness, lower TAPSE (Chart 1B) and longitudinal strain of RV lateral wall also correlates with increased functional class (Chart 1C), and these parameters are suggestive of progressive RV dysfunction.

Comparison with patients with pulmonary hypertension of other etiologies (primary, caused by mitral valvulopathy, caused by pulmonary embolism) showed pronounced pulmonary artery dilatation in patients with SIPH, some with aneurysm, as shown in Figure 3. This aspect was observed by other authors with reports of pulmonary artery dissection. ${ }^{17,18}$ The cause remains unclear, but it seems to relate to the chronic course of the disease, with gradual remodeling of the pulmonary artery, leading to the formation of inflammatory processes in the intima layer.

Comparing the echocardiography with the hemodynamic study, the increased mean right atrial pressure correlates with increased volume, as well as with reduced longitudinal strain of the lateral wall. The right atrium plays an important role in RV function, increasing its volume and decreasing its strain when the ventricular chamber deteriorates, as shown by its relation with the RV variation of areas and the TAPSE. The TAPSE also correlates strongly with the RV longitudinal and transverse strain.

The ratio of the tricuspid regurgitation velocity and the RV full outflow tract velocity can be considered a marker of PVR, because it correlates with the pressure exerted by the RV and the flow going through the pulmonary artery. ${ }^{19}$ This ratio correlates with the PVR calculated by cardiac catheterization and may be an important marker of the pulmonary circulation level of impairment.

The decrease in LV GLS can be caused by abnormalities in RV contractility, which affects left ventricular function, or by the lower left output due to decreased pulmonary blood flow caused by pulmonary hyper-resistance, decreasing the LV function and changing its strain. A combination of both factors may also be the case.

Using the ST methodology to analyze the RV seems to demonstrate more clearly the abnormality of right ventricular function in patients with severe pulmonary hypertension,

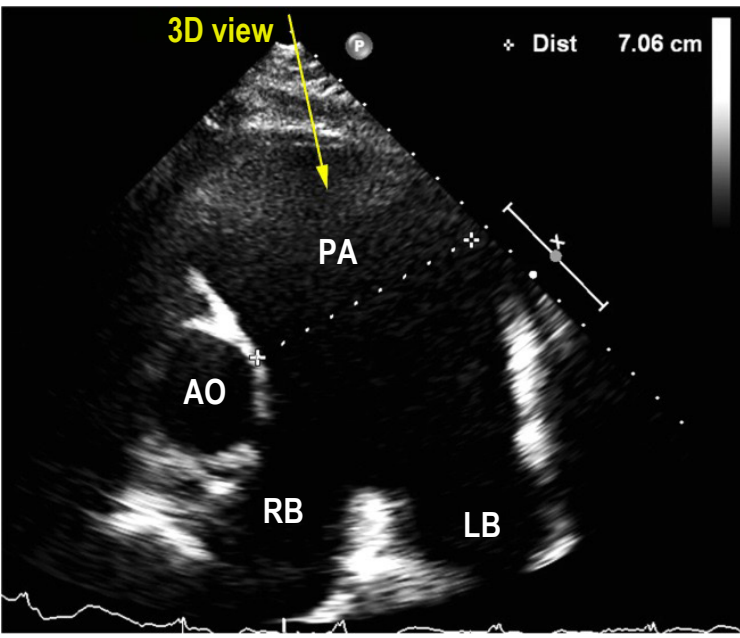

A

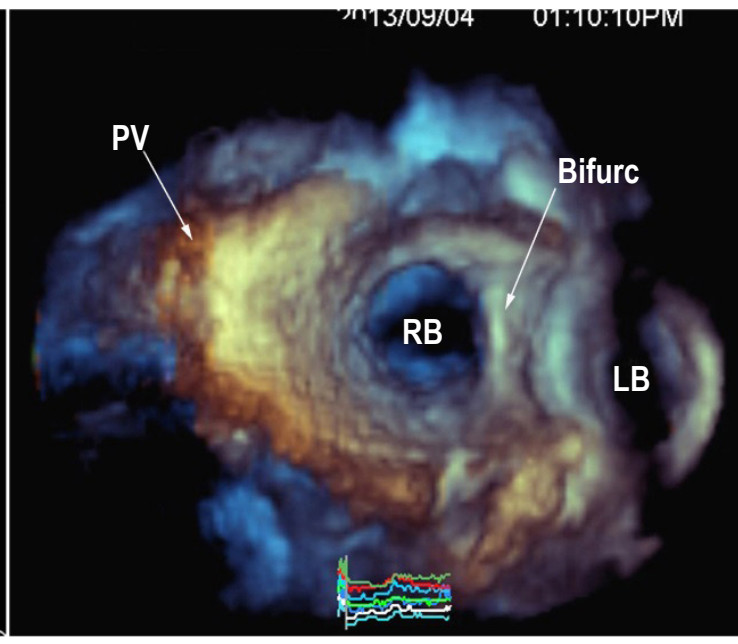

B

Figure 3-A-parasternal section imaging of patient with SIPH and aneurysmal dilatation of the pulmonary artery and branches. $B-3 D$ echocardiography of the same patient, where major dilatation of the pulmonary trunk and branches is observed. Note the irregularities in the pulmonary trunk wall. AO: aorta; PA: pulmonary artery; RB: right branch; LB: left branch; Bifurc.: bifurcation of pulmonary trunk; PV: pulmonary valve. 


\section{Original Article}

especially while analyzing the free wall of this cavity. The right ventricular systolic dysfunction is manifested by decreased longitudinal strain, more pronounced in the lateral wall. The transverse strain, which evaluates the radial strain of the walls, is increased in the SIPH side wall. The septal wall shows no significant increase. Increase in transverse strain can be attributed to RV remodeling, mainly due to hypertrophy of myocardial fibers deriving from the basal band. This type of fiber would be required to maintain right ventricular ejection against progressive increase in pulmonary resistance. The ventricular septum, mainly consisting of longitudinal and oblique fibers from the descending and ascending segments of apical band, has less circular fibers, which may explain the less significant changes observed in this wall.

The change from longitudinal strain pattern to circumferential strain pattern has been reported by Petersen et al. ${ }^{20}$ in patients with transposition of the great vessels operated using the Senning technique, where the RV is systemic. As the right ventricular myocardium has a predominance of longitudinal fibers virtually parallel, RV twisting is not observed, even when there is concentric remodeling.

\section{Limitations}

The main limitations are those inherent in the ultrasound method. Low quality pictures do not allow the correct analysis of strain and make it difficult to see the RV. Another limiting factor for the ST is the imaging frame rate, which should be at least $70 \%$ of the heart rate. Lower values are not correctly interpreted. The amount of ventricular segments suitable for analysis may also be a limiting factor. If more than three segments or two contiguous segments are not viewed, sensitivity of the method is impaired. ${ }^{21}$

\section{Conclusions}

Conventional echocardiography is useful to detect RV systolic dysfunction, showing correlation with functional class, TAPSE and RV variation of areas. Nevertheless, changes in right ventricular function assessed by two-dimensional strain appears to present a more significant difference than that observed by conventional echocardiography in detecting dysfunction caused by pulmonary hypertension. The main abnormalities consist in the decreased RV lateral wall longitudinal strain and increased transverse strain, probably due to right ventricular remodeling, which presents hypertrophy in response to pressure overload. This change in the RV strain pattern is an important marker of severity and impact of chronic pulmonary hypertension on the pulmonary vascular bed and on the right ventricular systolic function.

\section{Authors' contributions}

Research creation and design: Del Castillo JM; Data acquisition: Del Castillo JM, AMP Bandeira, Albuquerque ES, Lamprea DP, Mota Silveira CAM; Data analysis and interpretation: Del Castillo JM, AMP Bandeira, Albuquerque ES, Lamprea DP, Mota Silveira CAM; Statistical analysis: Del Castillo JM; Manuscript drafting: Del Castillo JM; Critical revision of the manuscript as for important intellectual content: Del Castillo JM, AMP Bandeira, Albuquerque ES, Lamprea DP, Mota Silveira CAM.

\section{Potential Conflicts of Interest}

There are no relevant conflicts of interest.

\section{Sources of Funding}

This study had no external funding sources.

\section{Academic Association}

This study is not associated with any graduate program.

\section{References}

1. Schwartz E. Pulmonary schistosomiasis. Clin Chest Med. 2002;23(2):433-43.

2. Schaberg T, Rahn W, Racz P, Lode H. Pulmonary schistosomiasis resembling acute pulmonary tuberculosis. Eur Respir J. 1991;4(8):1023-6.

3. Rocha RL, Pedroso ERP, Rocha MOC, Lambertucci JR, Greco DB, Ferreira CS. Chronic pulmonar form of schistosomiasis mansoni. Clinic- radiologic evaluation. Rev Soc Bras Med Trop. 1990;23(2):83-99.

4. Barbosa MM, Lamounier JA, Oliveira EC, Souza MV, Marques DS, Silva AA, et al. Pulmonary hypertension in schistosomiasis mansoni. Trans Roy Soc Trop Med Hyg. 1996 Nov-Dec;90:663-5.

5. Pedroso ERP. Lung changes associated with schistosomiasis mansoni. Inst Mem Inst Oswaldo Cruz. 1989;84(Suppl 1):46-57.

6. Zhou YG, Yang Z, Li DJ. The experimental study on pathological changes of pulmonary tissues in portal hypertensive rabbits with schistosomal cirrhosis. Zhonghua Wai Ke Za Zhi. 2005;43(9):587-90.

7. Martins RF, Bandeira AP. Hipertensão pulmonar secundária a doenças infecciosas e parasitárias. In: Guimarães JI(editor). Diretrizes da
Sociedade Brasileira de Cardiologia. Diagnóstico, avaliação e terapêutica da hipertensão pulmonar. [Citado em 2015 Dez 15] Disponível em: http://www.publicacoes.cardiol.br/consenso/2005/039.pdf

8. Fernandes CJC, Jardim C, Hovnanian A, Hoette S, Morinaga LK, Souza R. Schistosomiasis and pulmonary hypertension. In: Humbert M, Souza R, Simonneau G(eds). Pulmonary vascular disorders. Prog Respir Res. Basel, Karger, 2012; 41:143-8.

9. Hovnanian A, Hoette S, Fernandes CJC, Jardim C, Souza R. Schistosomiasis associated pulmonar hypertension. Int J Clin Pract Suppl. 2010 Jan;(165):25-8.

10. Lapa M, Dias B, Jardim C, Fernandes CJC, Dourado PMM, Figueiredo M, et al. Cardiopulmonary manifestations of hepatosplenic schistosomiasis. Circulation. 2009;119(11):518-23.

11. Tazar J, Haurigot MP, Caram R(h), Caram R, Haurigot GE. Funcion sistólica del ventrículo derecho em pacientes com hipertension pulmonar. Analisis com strain y strain rate. Insuf Card,Ciudad Autonoma de Buenos Aires. 2012;7(3):109-16. 
12. Torrent-Guasp F. Macroscopic structure of the ventricular myocardium. Rev Esp Cardiol. 1980;33(3):265-87.

13. Poveda F, Gil D, Marti E, Andaluz A, Ballester M, Carreras F. Helical structure of the cardiac ventricular anatomy assessed by diffusion tensor magnetic resonance imaging with multiresolution tractography. Rev Esp Cardiol (Engl Ed). 2013;66(10):782-90.

14. Ballester-Rodés M, Flotats A, Torrent-Guasp F, Carrió-Gasset I, Ballester-Alomar M, Carreras F, Ferreira A, Narula J. The sequence of regional ventricular motion. Eur J Cardio Thoracic Surg. 2006; 29(Suppl 1):S139-44.

15. Advanced hemodynamic monitoring. Orlando(Florida): Orlando Health Center; 2010. [Cited in 2015 Dec 15]. Available from: www.pdfdrive. net/advanced-hemodynaminc-monitoring-principles-and-practicein-e5902722 html

16. Schuller D. Clinical overview of pulmonaryarterial hypertension. Hosp Pharm. 2013; 48(Suppl 4):S1-S6
17. Lambertucci JR, Carvalho VT, Silva LCS. Pulmonary hypertension in schistosomiasis mansoni. Rev Soc Bras Med Trop. 2006; 39(3):295-6.

18. Corrêa RA, Silva LCS, Rezende CL, Bernardes RC, Prata TA, Silva HL. Pulmonary hypertension and pulmonary artery dissection. J Bras Pneumol. 2013;39(2):238-41.

19. Abbas AE, Fortuin FD, Schiller NB, Appleton CP, Moreno CA, Lester SJ. A simple method for noninvasive estimation of pulmonary vascular resistance. J Am Coll Cardiol. 2003;41(6):1021-7.

20. Petersen E, Helle-Valle T, Edvarsen T, Lindberg H, Smith HJ, Smevik B, etal. Contraction pattern of the systemic right ventricle: shift from longitudina to circumferential shortening and absent global ventricular torsion. J Am Coll Cardiol. 2007; 49(25):2450-6.

21. Mor Avi AV, Lang RM, Baldano LP, BelohlavekM, Cardim NM, Derumeaux G et al. Current and evolving echocardiographic techniques for the quantitative evaluation of cardiac mechanics: ASE/EAE Consensus Statement on Methodology and Indications. J Am Soc Echocardiogr. 2011;24(3):277-313. 